\title{
Coping Process in Children with Food Allergies Developing during Early Childhood
}

\author{
Misa Suzuki' ${ }^{1}$ Yuko Tomari² \\ ${ }^{1}$ Faculty of Nursing, Seisen University, Shiga, Japan \\ ${ }^{2}$ Faculty of Nursing, Osaka Medical University, Osaka, Japan \\ Email: suzuk-mi@seisen.ac.jp
}

How to cite this paper: Suzuki, M. and Tomari, Y. (2020) Coping Process in Children with Food Allergies Developing during Early Childhood. Health, 12, 38-62. https://doi.org/10.4236/health.2020.121004

Received: December 10, 2019

Accepted: January 14, 2020

Published: January 17, 2020

Copyright (c) 2020 by author(s) and Scientific Research Publishing Inc. This work is licensed under the Creative Commons Attribution International License (CC BY 4.0).

http://creativecommons.org/licenses/by/4.0/

\begin{abstract}
This study aimed to clarify the coping process in children who developed food allergies in early childhood and evaluate the nursing support required to enable the acquisition of independent care behaviors in children with food allergies. Semi structured interviews were conducted on 24 children (aged 11 - 15 years) with food allergies using the modified grounded theory approach. The 11 categories were identified as coping mechanisms that these children used to deal with their early childhood food allergies. The coping process in children with food allergies involved transition from a stage of viewing their allergy with fear to a stage of considering the allergy as manageable and thus tackling allergens in their own way in the Life model. The process required obtaining peace of mind with support from others. In addition to emphasizing the threat of food allergies and risk aversion behaviors to these children, it is important that nurses also communicate viable proposals for alternative behaviors for the prohibited actions. The results also suggest that children in school age or older require support to help them recognize food allergy-related issues as problem-oriented coping tasks from the viewpoint of both Medical and Life models.
\end{abstract}

\section{Keywords}

Food Allergies, Coping, Care Behavior, Modified Grounded Theory Approach

\section{Introduction}

Food allergies often develop during infancy, with a reported prevalence of about $10 \%$ for infants, approximately $5 \%$ for 3 -year-old children [1], and $4.5 \%$ for school-aged children [2] according to local surveys in Japan. Food allergies are caused by a wide range of foods, with symptoms ranging from mild skin irrita- 
tion to life-threatening events such as anaphylactic shock [3]. Depending on the type of allergy or allergen, there are some children who outgrow their allergies before preschool while others have symptoms that do not improve and transition into adolescence or adulthood. Some individuals also develop food allergies after school age [3], showing there are large differences in the course of this disease.

Over the past 2 decades, the circumstances surrounding food allergies have changed. Strategies to address food allergies in Japan have advanced over the past 20 years [4], such as the implementation of a food labeling system that includes allergens (2002), the improvement of medical treatment guidelines [5], and reimbursement for oral food challenge testing (2006). In addition, in the mid-2000s, the concept of oral immuno-therapy was repopularized in Europe, America, and Japan along with the more wide-spread use of oral food challenges. The basic attitude regarding medical care for food allergies also shifted from the previous "complete elimination of the causal food" to the "minimum necessary elimination of the causal food" based on the correct diagnosis using oral food challenge tests and other techniques [4].

Children with food allergies are naturally in the middle of these developments. Oral food challenges are indispensable tests and are performed by providing a fixed quantity of food that includes the allergen being assessed. Oral food challenges are designed to evaluate the induction of symptoms and symptom induction thresholds, the safe ingestible quantity of the allergen, and the severity of symptoms. Children are usually required to eat foods that they previously avoided and face the risk of developing serious symptoms from an allergic reaction during an oral food challenge. These, along with the disease characteristics of food allergies and the cognitive and developmental characteristics of children, may place a psychological burden on children with food allergies and affect their coping behaviors for this condition.

The theory of cognitive appraisal of stress by Lazarus et al. [6] suggests that cognitive assessment of an individual's perception of stressors strongly influences individual differences in stress responses and coping behaviors exhibited in stressful situations.

To evaluate support for the independent care behaviors of children with food allergies, it is important to understand the coping process based on how children perceive their disease, how they cope with and spend their days with their disease, their cognitive development, and the disease characteristics of food allergies among children with this condition. Previous studies did not sufficiently address the concrete experiences of children with food allergies and the process of coping.

\section{Objectives of the Study}

The objective of this study was to elucidate the experiences that children associate with food allergies as they grow and develop, as well as how they perceive and cope with their disease in order to evaluate the nursing care required to help 
these children acquire independent care behaviors.

\section{Study Methods}

\subsection{Definition of Terms}

\subsubsection{Children with Food Allergies}

In this study, food allergies were defined as phenomena in which adverse symptoms are induced in an organism through antigen-specific immunological reactions caused by food [4]. Children with food allergies in this study were defined as those previously diagnosed by a pediatrician or allergist in accordance with the aforementioned definition.

\subsubsection{Coping Process in Children}

This is the process in which children who develop food allergies in early childhood make an effort to handle their own food allergies, as well as the experiences and emotions accompanying food allergies.

\subsection{Target Patients}

\subsubsection{Criteria for Selecting Eligible Target Patients}

Target patients for this study were children with food allergies who met criteria [1] [2] [3] [4] below and their caregivers. Consent to participate was obtained from the caregivers and children themselves.

1) Those for whom a caregiver self-reported that an allergist or pediatrician had diagnosed the child with food allergy during infancy;

2) Those who required allergen control of one or more foods between infancy and school age;

3) Those at a cognitive developmental stage ranging from 11 to 15 years of age in the formal operational stage from Piaget's theory of cognitive development;

4) Those without diagnosis of delays in cognitive developmental and who can respond to interviews lasting approximately $60 \mathrm{~min}$.

\subsubsection{Method of Recruiting Study Participants}

An overview of the study was explained by e-mail or telephone, and the referral of potential study participants was requested from the representatives of organizations of parents of children with food allergies, non-profit support organizations for children with food allergies, and junior high schools attended by children with food allergies in the Kinki and Tokai areas located in the central part of Japan.

Then, documents requesting cooperation with the research were distributed to children and caregivers who were candidates for the research by representatives of each organization and school, detailing the research overview and the request for research cooperation.

Children and caregivers of children with food allergies were asked to contact researchers if they agreed to participate in the study.

The parents who subsequently contacted researchers were then given written or verbal explanations of the study overview by the researchers. 
Interview surveys were administered when the researchers determined that the patient selection criteria were met, on obtaining the consent of the children and caregivers.

\subsection{Survey Method}

\subsubsection{Interview Survey}

Prior to interviewing the children, caregivers were interviewed first to ascertain basic information such as the present history of food allergies.

Researchers asked children to recall their childhood experiences with food allergies and conducted a semi-structured interview based on an interview guide. Interviews lasted between 45 and 60 min per child.

The interview guide was prepared by taking into account the self-regulatory model and the concept of illness cognition proposed by Leventhal et al. [7] which considers the degree of language comprehension of the child. The content of the interview guide included the following: "episodes of physical illness caused by food, and what they felt, thought, and how they behaved at that time", "what they know about and what they were taught about their illness (food allergy)", "what they usually feel and think about their food allergy, and how they tackle their food allergies while carrying on with their daily lives at school or at home". At the beginning of the interview with the children, each child was asked about their general school situation and the reactions and linguistic expression of each child were observed in order to form a relationship between the children and researchers. If children requested, caregivers were allowed to be present at the interview, but were asked to refrain from commenting. The interview was recorded using a digital recorder with the permission of both caregivers and children.

\subsubsection{Analytical Methods}

Analyses of the data were performed using the modified grounded theory approach (M-GTA) proposed by Kinoshita [8]. The M-GTA is a study method that uses an approach developed by Kinoshita based on the original version of the grounded theory approach (GTA) developed in the 1960s [8]. The purpose of this study was to clarify the characteristics of the cognitive development process and the experiences of children with food allergies, the phenomenon of illness perception, and a series of processes consisting of interactions between children, families, and society. Thus, the M-GTA analytical method, which is a theory relying on social interaction and is exceptional at explaining and predicting human behavior, was utilized.

The focus of our analysis was "children aged $11-15$ years who developed food allergies during early childhood and still required allergen control for one or more food allergies". The analytic themes were "the process of coping in which children who developed food allergies during early childhood recognized their own food allergies, and learned to live with food allergies".

In the analysis, concepts were generated according to the analytic theme from 
verbatim records obtained during interviews and an analysis worksheet was created for each concept. The analysis worksheet described each concept, its definition, variations, and included theoretical notes. Each concept was interpreted from the viewpoints of the analytic theme and analytic focus, and confirmation of opposite and similar examples was carried out in parallel with the data collection. Comparisons were made between concepts, and data collection and analysis continued until theoretical saturation was confirmed.

Next, the mutual relationship between concepts was examined, categories that described the relationships between multiple concepts were generated, and a diagram that showed the relationships between categories was created. The resulting diagram was written using refined categories to complete the storyline. Theoretical sampling of study participants based on age, sex, food allergy symptom severity, and parental care attitudes was carried out. In the process of our analysis, attempts were made to ensure the appropriateness of the results by consulting experts familiar with qualitative research and pediatric nursing.

\subsection{Ethical Considerations}

This study was conducted after obtaining approval from the institutional review board of Osaka Medical College (approval number: KAN-94 [2463]).

Caregivers and children participating in the study were free to participate in the study, to withdraw consent at any time even after expressing their willingness to participate, and would not experience any negative consequences if they declined to participate. To reduce the psychological burden of the interviews on the children, caregivers were asked in advance about their child's present allergy history and were asked if the children would be able to talk about the presence or absence of severe symptoms such as anaphylaxis and episodes associated with these symptoms.

As an ethical consideration for the children, the study method was explained to children whose caregivers had consented to research in language that children could understand; consent to participate and undergo questioning was obtained from the children. To reduce the psychological burden on the children, consideration was also given to matters such as having a normal conversation prior to the survey and allowing caregivers to be present during the interview if children expressed such a preference. The interview was terminated if the patient appeared unwilling to answer questions. Recording was performed with the consent of the caregivers and children.

\section{Results}

\subsection{Interview Period}

From July 2018 to May 2019.

\subsection{Summary of Study Participants (Table 1)}

All study participants were Japanese. There were 24 participants, 18 male and 6 
Table 1. Summary of study participants.

\begin{tabular}{|c|c|c|c|c|c|c|c|c|}
\hline \multirow[b]{2}{*}{ ID } & \multirow[b]{2}{*}{ Age } & \multirow[b]{2}{*}{ Gender } & \multirow[b]{2}{*}{ Allergy } & \multicolumn{2}{|c|}{ Symptoms } & \multicolumn{3}{|c|}{ Treatment options } \\
\hline & & & & Anaphylaxis & $\begin{array}{c}\text { Anaphylactic } \\
\text { shock }\end{array}$ & $\begin{array}{l}\text { Elimination of } \\
\text { the causal food }\end{array}$ & $\begin{array}{l}\text { Oral food } \\
\text { challenge }\end{array}$ & $\begin{array}{c}\text { Oral } \\
\text { immunotherapy }\end{array}$ \\
\hline $\mathrm{A}$ & 15 & $\mathrm{~F}$ & Egg, Fish, Fish roe & $\mathrm{O}$ & - & $\mathrm{O}$ & $\mathrm{O}$ & $\mathrm{O}$ \\
\hline $\mathrm{B}$ & 14 & M & Peanuts, Fish, Strawberries & $\mathrm{O}$ & $\mathrm{O}$ & $\mathrm{O}$ & $\mathrm{O}$ & $\mathrm{O}$ \\
\hline $\mathrm{C}$ & 13 & M & Egg & $\mathrm{O}$ & - & $\mathrm{O}$ & $\mathrm{O}$ & - \\
\hline $\mathrm{D}$ & 14 & M & Egg, Milk & $\mathrm{O}$ & - & $\mathrm{O}$ & - & - \\
\hline $\mathrm{E}$ & 13 & M & Peanuts, Milk, Wheat & $\mathrm{O}$ & - & $\mathrm{O}$ & $\mathrm{O}$ & - \\
\hline $\mathrm{F}$ & 14 & M & Egg, Crustacean shellfish & $\mathrm{O}$ & - & $\mathrm{O}$ & $\mathrm{O}$ & - \\
\hline G & 13 & M & Wheat, Egg & $\mathrm{O}$ & - & $\mathrm{O}$ & $\mathrm{O}$ & - \\
\hline $\mathrm{H}$ & 14 & M & Peanuts, Tree nuts & $\mathrm{O}$ & - & $\mathrm{O}$ & $\mathrm{O}$ & - \\
\hline I & 12 & M & Egg, Fish, Buck wheat & O & O & O & O & - \\
\hline $\mathrm{J}$ & 15 & M & Egg, Milk, Peanuts, Buck wheat & $\mathrm{O}$ & $\mathrm{O}$ & $\mathrm{O}$ & $\mathrm{O}$ & $\mathrm{O}$ \\
\hline $\mathrm{K}$ & 14 & M & Buck wheat, Tomato, Banana, Apple & $\mathrm{O}$ & - & $\mathrm{O}$ & $\mathrm{O}$ & - \\
\hline $\mathrm{L}$ & 15 & $\mathrm{~F}$ & Egg, Wheat, Fish, Milk, Peanuts, Tree nuts & $\mathrm{O}$ & $\mathrm{O}$ & $\mathrm{O}$ & $\mathrm{O}$ & - \\
\hline M & 13 & M & Milk, Egg & $\mathrm{O}$ & - & $\mathrm{O}$ & $\mathrm{O}$ & $\mathrm{O}$ \\
\hline $\mathrm{N}$ & 12 & M & Milk, Japanese mountain yam & $\mathrm{O}$ & - & O & $\mathrm{O}$ & $\mathrm{O}$ \\
\hline $\mathrm{O}$ & 13 & M & Egg, Milk & O & - & O & O & O \\
\hline $\mathrm{P}$ & 12 & M & Wheat, Egg, Milk, Tree nuts, Buck wheat, Fish & O & O & O & O & O \\
\hline $\mathrm{Q}$ & 12 & M & Wheat, Egg & O & $\mathrm{O}$ & $\mathrm{O}$ & $\mathrm{O}$ & $\mathrm{O}$ \\
\hline $\mathrm{R}$ & 13 & M & Egg & $\mathrm{O}$ & - & $\mathrm{O}$ & $\mathrm{O}$ & - \\
\hline S & 14 & $\mathrm{~F}$ & Egg, Crustacean shellfish & $\mathrm{O}$ & O & O & $\mathrm{O}$ & $\mathrm{O}$ \\
\hline $\mathrm{T}$ & 11 & $\mathrm{~F}$ & Egg, Milk & $\mathrm{O}$ & - & $\mathrm{O}$ & $\mathrm{O}$ & $\mathrm{O}$ \\
\hline $\mathrm{U}$ & 12 & $\mathrm{~F}$ & Wheat, Egg & O & - & O & O & - \\
\hline $\mathrm{V}$ & 11 & M & Egg, Milk, Tree nuts, Japanese mountain yam & $\mathrm{O}$ & - & $\mathrm{O}$ & $\mathrm{O}$ & $\mathrm{O}$ \\
\hline $\mathrm{W}$ & 13 & M & Wheat & $\mathrm{O}$ & $\mathrm{O}$ & $\mathrm{O}$ & $\mathrm{O}$ & $\mathrm{O}$ \\
\hline $\mathrm{X}$ & 11 & $\mathrm{~F}$ & Tree nuts & $\mathrm{O}$ & $\mathrm{O}$ & $\mathrm{O}$ & $\mathrm{O}$ & - \\
\hline
\end{tabular}

female with a mean age of 13.0 years (range: $11-15$ y) from fifth-grade elementary school students to third-year junior high school students undergoing mandatory education in Japan. All of the participants lived in urban or suburban areas with limited access to medical institutions.

Food allergy symptoms that they reported experiencing included skin and mucosal symptoms, respiratory symptoms, gastrointestinal symptoms. All participants had experienced anaphylactic symptoms due to food allergies and nine had experienced symptoms of anaphylactic shock. All participants followed food elimination diets and underwent hematological testing for food allergies. Of all the participants, 23 had undergone oral food challenges and 12 had undergone oral immunotherapy (slow and rapid). 
All of the participating children were covered by public health insurance and were able to receive public health expenditure grants to cover their medical costs.

\subsection{Storyline}

A comprehensive diagram of the results (Figure 1) showing the relationship between storylines was created, and the storylines were prepared as follows, with categories indicated by brackets.

Children who developed food allergies during early childhood referred to food allergies as somebody else's business and did not recognize food allergies as their own disease.

Children who had undergone group activities such as being in nursery school "noticed 'their allergies' because they were different from others" and had accumulated experience in "understanding their 'own allergy' from the knowledge they were taught and their somatic sensations".

However, children who became aware of and understood food allergies independently felt a "vague fear of allergens" and subsequently attempted to "eliminate the allergen that was the object of their fear" and threatened their entire lifestyle as a way of coping.

Children who developed severe food allergies in early childhood did not experience symptoms under the strict allergy controls implemented by their parents. As a result, these children attempted to "eliminate the allergen that was the object of their fear" as a way to cope because it threatened their lifestyle. They were motivated by a "vague fear of allergens" that was deeply impressed on them because of their parents repeatedly conveying the need to avoid danger even before they understood their allergies themselves or became aware of it through somatic sensation.

Children who developed food allergies in early childhood constantly reported a "fear of allergens that they could not handle themselves" because they were still young, despite taking actions such as "understanding their 'own allergy' from knowledge that they were taught and their somatic sensations" and "eliminating the allergen that was the object of their fear". However, these children did not report being constrained by this experience as they felt secure because they were protected by adults during their daily lives by "seeking safety and security for themselves and getting substantial support from adults".

With substantial support from adults, children who gained peace of mind and safety began to "challenge their allergens through trial and error" at various levels after school age. Through this experience, children gradually gained "developing an awareness that the threat of allergens could be minimized", resulting in the "learning of skills to live well without being constrained by allergies". Children repeated these cognitive and coping cycles to deepen their cognitive and coping skills.

The act of coping by "seeking safety and security for themselves and getting substantial support from adults" in children continued until the end with gradual 


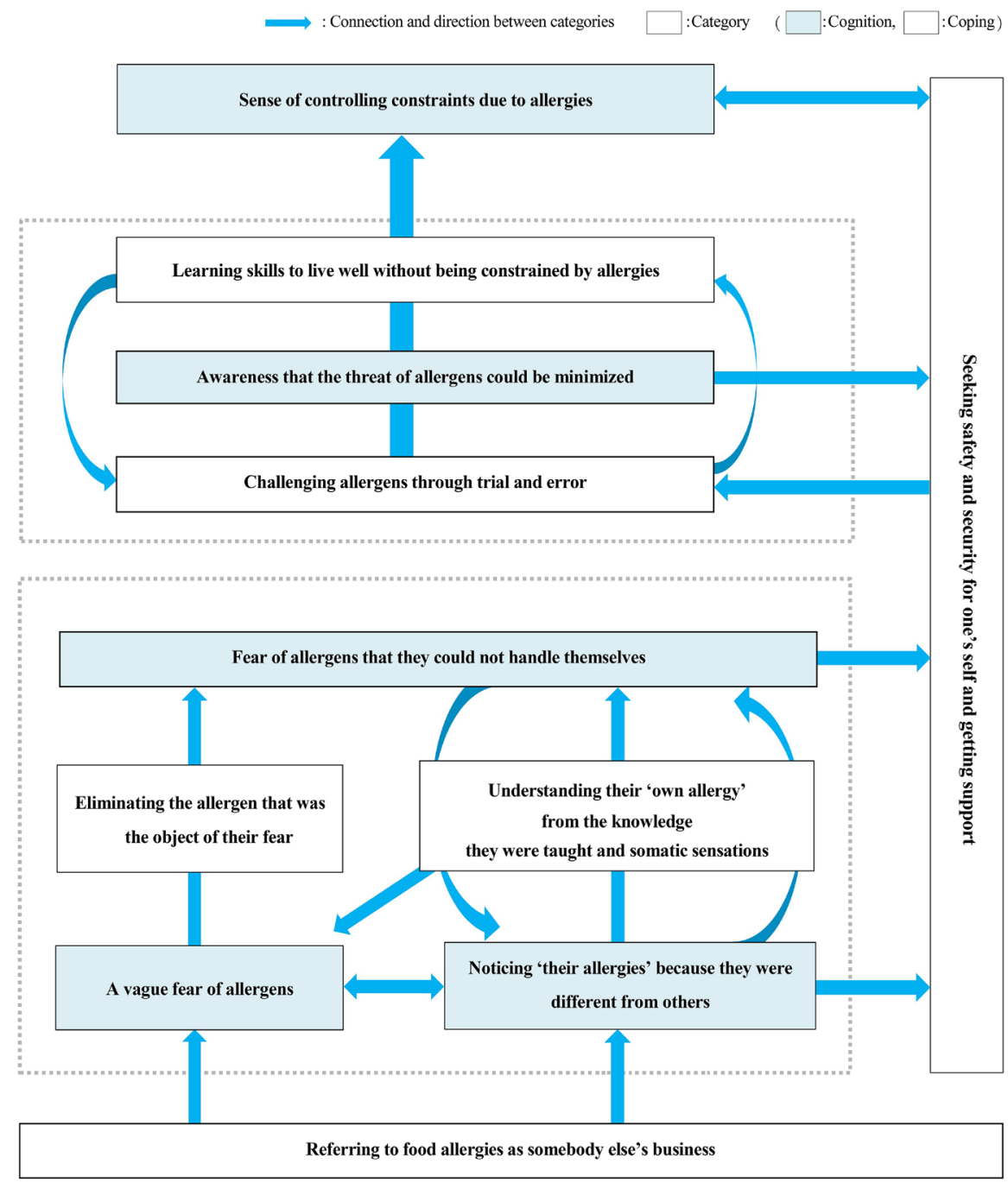

Figure 1. Coping process in children with food allergies developing during early childhood.

changes in the scope and content of support toward independence throughout the process of cognition and coping with food allergies.

The coping process of children with food allergies was ultimately associated with the acquisition of a "sense of allergy control" that enabled them to live without being constrained by fear of various allergens and allergic symptoms, while obtaining the support necessary to ensure security and safety for themselves up to the preadolescent stage.

\subsection{Categories and Concepts (Table 2)}

A total of 29 concepts were generated and classified into 11 categories with similar semantic content.

Hereinafter, categories have been denoted by [] brackets, concepts have been denoted by $<>$ symbols, interview content from study participants have been denoted by [italics], and participant IDs have been indicated by () parentheses. 
Table 2. Categories and concepts that constitute coping process.

\begin{tabular}{|c|c|}
\hline Category & Concept \\
\hline Referring to Food Allergies as Somebody Else's Business & $\begin{array}{l}\text { Not understanding anything at a young age } \\
\text { Having prior allergic episodes deeply impressed on them by parents } \\
\text { Leaving the control of food allergies to someone else }\end{array}$ \\
\hline $\begin{array}{l}\text { Noticing “Their Allergies" Because They Were Different from } \\
\text { Others }\end{array}$ & $\begin{array}{l}\text { Having food allergies meant the inability to eat with everyone } \\
\text { Realizing their difference from everyone else and that the "normal for them" } \\
\text { should be reinterpreted as "their allergy" }\end{array}$ \\
\hline $\begin{array}{l}\text { Understanding Their "Own Allergy" from the Knowledge They } \\
\text { Were Taught and Somatic Sensations }\end{array}$ & $\begin{array}{l}\text { Understanding how to distinguish foods that can be eaten } \\
\text { Not missing sensory changes identified by somatic sensations } \\
\text { Learning how to cope with symptoms from adults }\end{array}$ \\
\hline A Vague Fear of Allergens & $\begin{array}{l}\text { Allergies are linked to the ultimate threat of death by adults } \\
\text { Allergens are something to loathe and fear }\end{array}$ \\
\hline Eliminating the Allergen That Was the Object of Their Fear & $\begin{array}{l}\text { Eliminating allergens from their surroundings so that these allergens could not } \\
\text { be enter safe areas }\end{array}$ \\
\hline Fear of Allergens That They Could not Handle Themselves & $\begin{array}{l}\text { Feeling at a loss due to unexpected and unseen allergens that emerge contrary to } \\
\text { expectations } \\
\text { Being unable to express changes that continue to occur in the body in one's own } \\
\text { words }\end{array}$ \\
\hline Seeking Safety and Security for One's Self and Getting Support & $\begin{array}{l}\text { Establishing safety and security for one's self with the help of adults } \\
\text { Establishing safety and security for one's self }\end{array}$ \\
\hline Challenging Allergens through Trial and Error & $\begin{array}{l}\text { Challenging allergens } \\
\text { Linking changes in the physical condition starting from discomfort with allergies } \\
\text { Finding the danger line for one's own body through trial and error } \\
\text { Conflict with taking in allergies }\end{array}$ \\
\hline Awareness That the Threat of Allergens Could Be Minimized & $\begin{array}{l}\text { Understanding how my allergy appears } \\
\text { The target of fear due to allergies becoming limited }\end{array}$ \\
\hline $\begin{array}{l}\text { Learning Skills to Live Well without Being Constrained by } \\
\text { Allergies }\end{array}$ & $\begin{array}{l}\text { Learning that comes from the lessons of parents and experiences that take root } \\
\text { Having one's own coping routines for allergy management } \\
\text { Judgment about allergies fluctuating in the context of relationships with others } \\
\text { Learning skills to get along well with friends without being overly restrained by } \\
\text { allergies }\end{array}$ \\
\hline Sense of Controlling Constraints Due to Allergies & $\begin{array}{l}\text { Food allergies as part of one's own uniqueness } \\
\text { Not always being sick } \\
\text { Accepting the limitations of one's own food allergy } \\
\text { Finding happiness in the allergy-friendly world }\end{array}$ \\
\hline
\end{tabular}

\subsection{1. [Referring to Food Allergies as Somebody Else's Business]}

[Referring to food allergies as somebody else's business] means the child did not recognize that he/she had a food allergy during early childhood and that various restrictions were required, and that he/she did not consider all matters related to food allergies because he/she treated it as somebody else's business. This consisted of three concepts: $<$ not understanding anything at a young age $>,<$ having prior allergic episodes deeply impressed on them by parents $>$, and <leaving the control of food allergies to someone else>.

$<$ Not understanding anything at a young age $>$

[ I do not remember much, but I did hear about it (having allergies) since age 
0. I did not understand much when I was younger, and all I knew was that I could not eat something.] ( ID A)

$<$ Having prior allergic episodes deeply impressed on them by parents $>$

[ I was told, by my mother, that I nearly suffocated when I was young. Maybe one time, around when I was still a baby, I ate something I shouldn't have. One other time, I ate peanuts at my friend's home and it apparently turned out to be no laughing matter.] (ID E)

$<$ Leaving the control of food allergies to someone else $>$

[ When I was young, my mother chose (the things I ate) for me.] (ID A)

[ Well... Most of the time my parents decide. I was basically like, anything is fine.] $(I D K)$

\subsection{2. [Noticing "Their Allergies" Because They Were Different from Others]}

[Noticing "their allergies" because they were different from others] indicated that, when comparing themselves to others while living in a group setting, participants noticed that they were different and recognized that this was because of food allergies. This category included two concepts: <having food allergies meant the inability to eat with everyone $>$ and $<$ realizing one's difference from everyone else and that the "normal for them" should be reinterpreted as their allergy>.

$<$ Having food allergies meant the inability to eat with everyone>

[ When I was in nursery school, I and one other child had allergies, and I would eat together with that child, just the two of us, at a desk separate from the desks of the other children. The time I was at nursery school, I remember feeling very sad because I could not eat meals with my friends.] (ID A)

$<$ Realizing their difference from everyone else and that the "normal for them" should be reinterpreted as "their allergy" $>$

[All the other children ate castella during snack time at the nursery school, while $I$ and one other child would eat potato chips. I wondered why and I thought that it would be better to eat castella. I did not realize it at first because I ate the same snacks as my siblings at home, but then I realized it was because I was allergic that I had to eat something different. I think that is the oldest memory I have of when I was young.] (ID R)

\subsection{3. [Understanding Their "Own Allergy" from the Knowledge They Were Taught and Somatic Sensations]}

[Understanding their "own allergy" from the knowledge they were taught and somatic sensations] indicates gaining a sense of understanding of their food allergies from parents and trusted adults by learning how to identify what to eat and coping with symptoms and experiencing and judging changes in their bodies. This consisted of three concepts: <understanding how to distinguish foods that can be eaten $>$, <not missing sensory changes identified by somatic sensations $>$, and $<$ learning how to cope with symptoms from adults $>$.

$<$ Understanding how to distinguish foods that can be eaten $>$ 
[If there's egg in there, it would be a yellowish food. Or I would look at the color or shape of the food. I basically picked what I could eat visually.] (ID H)

[ When I went shopping with my mom, I asked "where the things I could not eat were written?" and she told me "it's here" by pointing to the food labeling.] $(I D Q)$

[My mother told me to "look for myself" and showed me the food labels and I looked at them. I had been looking at labels from the time I was very small, so, although I could not write the characters (for eggs), I could somewhat tell by the mark and the shape of the characters. Then, after a while, I realized I could tell it meant eggs or milk.] (ID V)

[My parents taught me that it was okay to eat the eggs in this confectionery because it was cooked.] (ID W)

[There are many types of eggs, like egg whites, egg yolks, and egg shells. There's eggshell calcium too. So, if I am not sure if I can eat it even after looking at the ingredients, then I should stop.] (ID U)

<Not missing sensory changes identified by somatic sensations>

[(If I eat foods containing allergens), I slowly get these reddish raised spots. Around here (around the chest), there's this overwhelming sensation and I feel like I $m$ turning into an unusual monster, and I feel sick. Then, the tips of your hands turn white, and sometimes you don't feel anything or sometimes your fingers do not move. Sometimes you feel somewhat light-headed or feel sick. Well, during those times, I know something (allergy symptoms) is happening so I call my parents right away.] (ID Q)

[If I consume milk and feel the taste on my tongue, the feeling in my mouth would be really weird. It's also not only when you drink milk itself, but also if you eat cookies or drink soups, I can tell that "there is milk in there" by the strange feelings in my mouth. It feels like a sensor on your tongue, so I can feel it right away. So, right now, I don't really eat things I shouldn't eat by mistake.] $(I D W)$

\section{<Learning how to cope with symptoms from adults>}

[My mom always tells me what to do, like take this medicine when you get hives, and do this when you have more severe symptoms. When I ate these sweets that contained wheat, my mom said to take the medicine just in case even, if I didn't get symptoms for a while after eating, so I take it.] (ID L)

[ The doctors at the hospital explained how to take the medicines and about

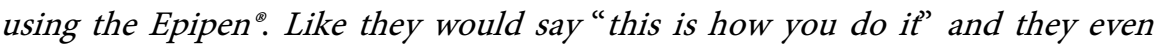
taught me how to inject myself, so I basically know what to do.] (ID W)

\subsection{4. [A Vague Fear of Allergens]}

Having [a vague fear of allergens] means that the participant could not identify the appearance or shape of an allergen or know specifically about the allergy but recognized the allergen or allergy as something to fear or avoid that may lead to death, without complete comprehension. This category consists of two concepts: $<$ allergies are linked to the ultimate threat of death by adults $>$ and <allergens are 
something to loathe and fear>.

<Allergies are linked to the ultimate threat of death by adults>

[ When I touched the peanuts, I was told (by my mother) no, and when I asked "why?" she said that "Because... if, you ate peanuts, you would die".] (ID E)

$<$ Allergens are something to loathe and fear>

[ I don't know how it happened at all, but, from a certain time, I really started hating eggs. It's not like I can't eat it at all, since if the egg is completely cooked rather than half-cooked, I could probably eat it, but even if that's the case I already hate all of it. I think it may be something like an object of fear, like I feel like $I m$ afraid of it.] (ID E)

[ I really don't know what a peanut really looks like. I only have an image of the shell. It's like I $m$ so afraid of it so P ve avoided looking at it.] (ID E)

[It's like it's always been, if foods (food ingredient tables) have the character for egg, that means they are all enemies. At least for me.] (ID V)

\subsection{5. [Eliminating the Allergen That Was the Object of Their Fear]}

[Eliminating the allergen that was the object of their fear] means avoiding allergens recognized as a threat to their safety and security by putting physical and psychological distance between themselves and the allergen in order to protect themselves. This consists of the concept of <eliminating allergens from their surroundings so that these allergens could not enter safe areas $>$.

$<$ Eliminating allergens from their surroundings so that these allergens could not be enter safe areas $>$

[(When I was little) I would avoid food that gave me allergies as much as possible and would not touch it as much as possible.] (ID A).

[ $I$ even avoided looking at peanuts. At a younger age, I felt that even having peanuts in the same space was intolerable and something I had to avoid. I was always worried if" any food around me had peanuts in it".] (ID E)

[ I don't eat it. I would never eat it again.] (ID F)

[ I was so worried that I was even afraid of inhaling the soba flour, so I would hold my breath when I walked the street in front of the soba restaurant.] (ID K)

\subsection{6. [Fear of Allergens That They Could Not Handle Themselves]}

[Fear of allergens that they could not handle themselves] means being confused and fearful of allergens that cannot be seen, anticipated, or expressed, even if there is a gradual gaining of understanding and an attempt to make a judgment regarding the allergen or allergy through experience. This consists of the following two concepts: <feeling at a loss due to unexpected and unseen allergens that emerge contrary to expectations $>$ and $<$ being unable to express changes that continue to occur in the body in one's own words $>$.

$<$ Feeling at a loss due to unexpected and unseen allergens that emerge contrary to expectations $>$

[If I ate something I thought I could finally eat and find out that I could not, I would be surprised. If I think "this is something I should be able to eat", but if I unexpectedly feel itchy or develop symptoms, it feels like I no longer understand 
my own body.] (ID $A)$

$<$ Being unable to express changes that continue to occur in the body in one's own words>

[Even if something was wrong, I could not say anything (to the nurse). Sometimes my throat would hurt, like something was coming, but then I would think I may have just drank too much water. I would get strange spots, I would think it was maybe because I scratched it. My stomach would hurt, and I would think it was because I ate too much. Sometimes I would think it was something, but then it would get better. I have a difficult time expressing things verbally. It is difficult to use words to convey things.] (ID B)

\subsection{7. [Seeking Safety and Security for One's Self and Getting Support]}

[Seeking safety and security for one's self and getting support] indicates the act of seeking and attempting to establish security and safety in order to live a life that is not threatened by food allergies with the help of parents, trusted adults, friends, and one's self, even while having food allergies. This consists of the following two concepts: <establishing safety and security for one's self with the help of adults $>$ and <establishing safety and security for one's self $>$.

<Establishing safety and security for one's self with the help of adults>

[Since I was younger, my mother has been taking care of my allergies, so she gets 100 points of confidence. The doctor at the hospital gets about 95 points. I know my mother gets it right more than I do, and I trust her.] (ID S)

[ I can definitely trust the food made by my parents. At home, I would listen to my dad and mom talking about how many minutes they cooked the fish while making meals, and I would know it's alright.] (ID $A$ )

<Establishing safety and security for one's self>

[Japanese sweets, gum and candies often do not contain eggs. If it's a type of food that doesn't have any allergens, it should be fine, and I can choose sweets that I want to eat from there.] (IDA)

[ I go to fast food places where the allergen labels are written clearly or to some place like an udon noodle restaurant where they have menu items that don't use eggs. I don't go to restaurants I have never been to before. I often ask for the same items at places 1 ve been to with my parents.] (ID F)

[ We asked for a cake that contains neither eggs nor milk for allergies, but when I ate the cake, my throat became itchy. That's why I can't trust that shop, and I will never go there again.] (ID O)

[The teacher told us to eat our lunch boxes together as a group, but at that time there wasn't any kid around me I could really trust. I would see kids forcibly exchanging (the sides in their lunch box), and I would think I "wouldn't want" to eat with that kid. It would be scary if they suddenly gave me the egg (the allergen). That's why I chose my friends carefully. I would carefully choose those kids who would really try to be understanding. I won't trust any kid who might do something crazy all of a sudden.] (ID F) 


\subsection{8. [Challenging Allergens through Trial and Error]}

[Challenging allergens through trial and error] means that children living day to day with restrictions associated with various allergies accept that they have food allergies and reassess food allergies as being something that can be challenged, realizing they can expand on what they can do or understand through repeating trial and error. This consists of the following four concepts: <challenging allergens $>$, <linking changes in the physical condition starting from discomfort with allergies $>$, <finding the danger line for one's own body through trial and error $>$, and $<$ conflict with taking in allergies $>$.

\section{$<$ Challenging allergens $>$}

[ There was a place where wheat was blown out with the wind (from the ventilation fan on the outer wall of a bread factory building). Since flour was blown out with the wind, my mom told me to stay away from it. I stood right in front of the ventilation fan and got wind (out of the fan) blown at me for 10 minutes, but nothing (symptoms) happened.] (IDQ)

[ I really wanted to eat, so I wanted to receive (specific oral immunotherapy). I wanted to eat what everyone was eating. Like when I see celebrities eating it, I would think "that looks really delicious", but I couldn't eat it. When I see my friends eating snacks, I would think "I wonder what that would taste like". That's why I wanted to be hospitalized and get treated (with specific oral immunotherapy), so I would become able to eat it.] (ID U)

[( With specific oral immunotherapy), once a day I could eat the amount the family doctor decided. I would measure the amount of wheat protein in the food based on the prescribed amount and change what I ate based on the day. I would measure the amount and decide what to eat myself. At first when I was in $3 \mathrm{rd}$ grade, my mother would do it, but when I was in 5 th grade, I ended up doing it myself.] (ID W)

$<$ Linking changes in the physical condition starting from discomfort with allergies $>$

[ I first discovered I had a crab allergy when I was exposed to the steam from the hot water in the crab pot and my face was suddenly very itchy. I thought, "What is it?" I saw there was a crab in there that wasn't normally included, so I immediately understood "crab?" I remembered the itching from my egg allergy, so I even told my mother that the "itching was like from my egg allergy". It seemed that the indescribable uncomfortable feeling transferred onto on my face.] (ID F)

[ I would try to recall the time before the allergic symptoms appeared, and I would recall everything, "What did I eat at that time, and what did I eat next?" After that I would think "this is okay because I eliminated it", and then I would realize, "Oh, it might be this rice cracker (allergy from it)". I would also look at all the snacks, and I would think "Oh, maybe these snacks are causing it and are dangerous".] (ID L)

<Finding the danger line for one's own body through trial and error>

[Around the time when I could finally eat almost raw eggs, when I was in my 
1 st year of junior high, I made pudding using raw eggs and milk. I thought I had cooked and heated it properly, but when I tried eating it, my throat became itchy, so I thought it was still raw inside. I didn't know what caused the itchiness, so I made it again. I tried to steam it for a long time on high heat the next time I made it, but when I still got itchy the 2 nd time in a row, I was surprised. I got flustered that it wasn't working out.] (ID A)

\section{<Conflict with taking in allergies>}

[From a certain point, I really started to hate eggs. If it was boiled eggs, I could probably eat them, but I really did come to hate them. My mother said, "If you do not eat eggs, you won't grow", and she would try to make me eat them, but I really do not want to.] (ID E)

[At first (when I was first hospitalized for oral immunotherapy), I was really scared. I really wanted to eat, but I was like "What if I die? I don't want to die", but then I thought we started this because I said "I really wanted to get immunotherapy". It was quite difficult (even when I went home and continued immunotherapy). I had to eat. I told my mom it was really hard, but I still had to keep going and the reason was because I wanted to be able to eat other things. I was trying to eat somehow, but I really didn't feel like eating.] (ID U)

\subsection{9. [Awareness That the Threat of Allergens Could Be Minimized]}

[Awareness that the threat of allergens could be minimized] means that an individual's allergy that had not been previously understood becomes clear through various experiences such that the boundary between the threat and non-threat can be understood and the individuals can feel that the fear and threat caused by the allergy to them is less than before. This consists of the following two concepts: <understanding how my allergy appears> and <the target of fear due to allergies becoming limited $>$.

\section{<Understanding how my allergy appears>}

[After about 30 minutes (of eating an allergen-containing food), you start feeling uncomfortable. After about one and a half hours, it's absolutely uncomfortable. The first part is the hardest, but it gradually wanes. If it is a bit worse, it would continue for a bit, but the feeling is about the same.] (ID D)

[At first, I feel an itch and, when I look there, I realize I have a rash. I don't know why, but it starts with my head; then my neck, arms, and upper body, and then the legs get itchy last, and it all gets itchier. It then slowly goes away. If I think "Oh, it's itchy", it's definitely coming, so I tell my parents and take some medicine.] (ID W)

\section{$<$ The target of fear due to allergies becoming limited>}

[ When I was younger, I would think "Oh, there may be peanuts in this", and then I would go "Oh, what should I do?" "P m going to die". Now, P m not so afraid of death like when I was younger, and I don't think immediately of dying. Well, not right away at least. Maybe, after a little bit. Even if it was an emergency, I think I would be able to last for a few minutes and, if I was taken to the hospital during that time, I would get better.] (ID E) 
[ They say I get symptoms, but it does not happen all that often; if I am careful, you shouldn't experience it. If I pay attention to the fact that there are rarely any of these problems, I don't get such symptoms. The only time I wasn't careful and symptoms appeared was probably when I ate the buckwheat cookies.] (ID K)

\subsubsection{0. [Learning Skills to Live Well without Being Constrained by Allergies]}

[Learning skills to live well without being constrained by allergies] indicates various improvements made with the aim of a pleasant life for one's self not controlled by allergies based on knowledge accumulated and self-coping methods for food allergies developed during early childhood. This consists of the following four concepts: <Learning that comes from the lessons of parents and experiences that take root $>$, <having one's own coping routines for allergy management $>,<$ judgment about allergies fluctuating in the context of relationships with others $>$, and <learning skills to get along well with friends without being overly restrained by allergies $>$.

$<$ Learning that comes from the lessons of parents and experiences that take root $>$

[My mother told me that I should avoid eggs over rice in the morning before competitions and tests as much as possible. I thought that I could also start getting itchy, so it would be better to stop too if I had a cold. I thought of that on my own.] (ID A)

$<$ Having one's own coping routines for allergy management>

[First, When I feel itchy (in my throat), lick ice, drink water, and just try to relieve the itching. Taking the ice, crushing it, and trying to keep it in the part of my throat that is itchy really make it better. If the itching does not subside, I take the medicine.] (ID A)

[ When the symptoms appear, drinking ordinary tea is not effective, and it actually feels a little worse. If I drink mixed fruit juice, it kind of gets better. Well, it may not actually be fine, but I felt better. If I start getting itchy, I drink that and try making a game out of it. I always do that.] (ID D)

[If I think I have allergic symptoms, drink tea afterward; if I still feel something is unusual, try not to move and watch TV. Moving around after eating eggs and such things makes it more likely for symptoms to appear, so I should just chill and wait until it passes.] (ID R)

$<$ Judgment about allergies fluctuating in the context of relationships with others $>$

[If I am at a friend's house and my friend's mom puts out food with allergens in it, I really can't say anything to my friend's mom since it's already after she has made the food. I know I should refuse, but I feel guilty, it is hard to say something. Before, when I went to a friend's home, they brought out cod roe pasta for lunch, and I was really worried. I avoided the cod roe as much as I could and ate it carefully. That time, it was all good, and I was grateful nothing happened.] (ID A) 
$<$ Learning skills to get along well with friends without being overly restrained by allergies $>$

[If I am at the food court of a shopping mall or something, I should be able to choose something that I can eat from one of the restaurants inside (even when I go with friends); it doesn't mean I can't eat anything together with them just because I have allergies.] (ID S)

[Recently, as part of the school events, it's more common to shop and eat with friends, so in such cases, I tell everyone about my allergies, research in advance, and encourage my friends to go to a restaurant that hopefully has something I can eat.] (ID A)

[During the school trip, we got eggs for breakfast. I have a friend who has a lot of likes and dislikes, who gave me a request to "exchange your side dish with mine". That's why I gave my fried egg to that kid. It surprisingly worked well for us. Yeah just like that! It works out like that sometimes.] (ID R)

\subsubsection{1. [Sense of Controlling Constraints Due to Allergies]}

[Sense of controlling constraints due to allergies] means that various restrictions and constrictions caused by one's own food allergy are accepted and that there is a feeling that one can deal with one's own allergy, including when things go well or badly or despite being free or not to do certain things. This consists of the following four concepts: $<$ food allergies as part of one's own uniqueness $>$, $<$ not always being sick $>$, <accepting the limitations of one's own food allergy $>$, and $<$ finding happiness in the allergy-friendly world $>$.

\section{$<$ Food allergies as part of one's own uniqueness $>$}

[It is obvious of course, but $1 \mathrm{~m}$ probably different from everyone else. It's an individual trait-a unique trait. I think that both good and bad individual traits are still considered individual traits.] (ID F)

[It's like everyone knows about it. That's why I think it is no big deal and having allergies is fine. I don't want to be treated specially or like $P \mathrm{~m}$ sick, and I don't need to be pitied. It's not like I want to eat but I can't. I actually don't want to eat it.] (ID R)

\section{$<$ Not always being sick>}

[ When I think of a disease, I think of cancer, leukemia, and something where I $m$ staying in bed all the time. That's why I think allergies are a disease, but not really a disease.] (ID $A$ )

[ When eating, I am conscious that I "have a food allergy", but I don't have to think about the allergy all the time at all other times.] (ID E)

\section{<Accepting the limitations of one's own food allergy>}

[I do think I want to eat, but I ve made peace with the fact that I can't eat everything that I want to. When I was little, I was more positive than now. When I was little, in the future, I thought my allergies would heal and I could eat anything. But I think that if I still can't eat these things now in junior high school, $P m$ likely never going to be able to eat them as an adult. $P$ ve learned to listen to that kind of stuff.] (ID A) 


\section{<Finding happiness in the allergy-friendly world>}

[ When I was younger, I thought I wanted to eat the same food as everybody. I do still think that about certain things, but as I get older, I no longer think $1 \mathrm{~m}$ that eager to eat the same food as everybody else. I think there are lot of things that can help deal with allergies, so I think it's all right now.] (ID L)

[ I can't eat omelets due to my allergy, but, even if $P$ m not able to eat it, it's like "oh well, it's alright". P m satisfied with that. That's why I don't feel it's necessary to treat me like I need to be pitied.] (ID R)

[ When I read an allergy book in the library, it's very interesting. They say there are allergies because the country is clean. There are worse things than allergies, that's why I think "having allergies is fine". I think $P$ m much better off.] $(I D R)$

\section{Discussion}

The change in the way allergy is perceived as a threat-as a core category in the process of children coping with food allergies-was evaluated.

\subsection{Changes in Children's Cognitive Assessment of Allergies}

\subsubsection{Recognition of Allergy as a Target of Fear or a Threat to One's Existence in Early Childhood}

Younger children with food allergies are considered not to be aware of themselves as having a disease-food allergies-as they consider food allergies somebody else's business.

Children with food allergies compare their social behavior and situations of "eating" with others when eating meals in groups, such as in nursery school. In such situations, food allergies are first recognized as "diseases" by "noticing one's allergies" because they are different from others. "Illness perception" is a preliminary step in coping with the disease [7]. After recognizing the presence of their own food allergies through differences from others, children in this study began to show coping behaviors, such as trying to understand the meaning of somatic perception due to food allergy symptoms and acquiring knowledge of allergies through "understanding 'their allergy' from the knowledge they were taught and their own somatic sensations".

Nonetheless, young children with anaphylactic symptoms due to food allergies were repeatedly taught by their parents that "even if other people can eat the food, they may die from eating it" before they became aware of their food allergy. Since allergy episodes heard from parents are deeply ingrained, this becomes the basis of the child's experience with allergies, and the children develop a "vague fear of the allergen" and take actions to cope by "eliminating the allergen that is the object of fears" to escape the vague yet absolute fear of allergies.

Considering that food allergies and treatment characteristics are the factors that affect children's coping processes, the following characteristics should be recognized: 1) the concepts of food allergies and allergens are abstract and complex, and these are difficult for children to understand; 2) foods that are suppo- 
sedly safe and trustworthy may have a dual aspect of threatening the child's health and well-being; 3) there is a lot of variability in allergens and allergic symptoms among individuals; 4) there is a lack of consistency in allergic symptoms due to influence of various factors; 5) allergic symptoms are not always observed and are usually present in a latent pathological state; however, there are instances when life-threatening symptoms suddenly appear; and 6) food allergy treatments also have a dual aspect of avoiding causal foods as a rule in food elimination therapy and taking in allergens as a rule in oral food challenge tests.

These characteristics interact with the characteristics of the children's cognitive development and were the factors that made it difficult to understand food allergies; these factors may lead to the recognition of allergy as a "vague fear of the allergen" and "fear of allergens that they could not handle themselves".

It is difficult for young children at risk of food allergies to implement care behaviors, including risk-avoiding behavior, by themselves based on their understanding of the disease of food allergy. Therefore, parents of children with anaphylactic symptoms due to food allergies believe their response to food allergy as a "battle against the death of the child" [9] and make the most use of the "fear" felt by children to educate and protect their children from life-threatening allergens [10]. As a measure to protect children from dangerous allergies in early childhood, parents may convey messages to young children that food allergies equate to an object of fear and encourage actions motivated by instinctive "fear".

However, there may be recurring situations in which children are subjected to having to listen to episodes of critical events from parents that they cannot recall, vague fears of death, inconsistent and poorly understood disease characteristics of food allergies, and cognitive developmental traits of early childhood, which can lead to these chaotically being linked to cognition in early childhood and leading to the "fear of allergens that they could not handle by themselves" becoming ingrained in the children's perception. Children with a strong tendency to perceive allergens as objects of fear have this fear as young children and also as teenagers, suggesting that the cognitive tendency of children to perceive allergens as fears and threats has a long-term impact on the child's coping process.

Lazarus' cognitive appraisal theory of stress states that if an individual considers something stressful, it is rated as a "harm/loss", "threat", or "challenge" [6]. "Threats" are characterized by negative emotions, such as fear, anxiety, and anger, and "challenges" include the possibility of growth and are accompanied by pleasurable emotions, such as enthusiasm and parental education (deliberately communicating the allergen to the child as a "threat" and promoting risk-avoiding behaviors as an emotional response) to promote risk-avoiding behaviors among young children, which have achieved the goal of distancing children from dangerous allergens and can be regarded successful.

However, parental education to strengthen awareness of allergens as threats seems to be an obstacle to taking independent and appropriate action to cope against chronic food allergies at a stage where it would be desirable to change the 
focus of coping behavior to cognitive coping efforts centered on problems rather than emotional coping behaviors.

According to Piaget's theory of cognitive development, the stages of cognitive development in school-age children ( 7 - 11 years) fall into the concrete operational period [11]. At this stage, direct and logical thinking regarding concrete objects becomes possible, and it is the stage in which thinking can occur in consideration of the properties of objects and in the perspective of the overall object.

Thus, it is important to promote cognitive coping efforts and not to impart bias toward emotional coping for providing long-term psychoeducational support to children from school age onwards, such that food allergies can be viewed from a positive point of view as a challenge and problem-centered coping can be achieved through logical thinking.

Children "seeking safety and security for one's self and getting support" demonstrated a dynamic process of growth and development whereby they exert their individual strength to reassess their allergens while obtaining security and safety from adults who are the subjects of absolute trust, thereby acquiring "challenging" coping behaviors, during the period from early childhood to school age and then to pre-puberty.

Security and safety required by children with food allergies during childhood are regarded as the achievement of a feeling of security and safety by receiving support for the management of food allergies from the adult. Additionally, security and safety sought by children from school age onward who are capable of more logical thinking seems to be that cultivated independently by the children themselves to allow self-efficacy in their daily lives under supervision of and educational support from the adult.

Based on the above, it is important for children to receive support for security and security from reliable adults in all processes of the stressful situation of coping with food allergies, and this feeling of security and safety obtained from the support of the adult becomes a basis for the child to advance the coping process linking to self-efficacy.

\subsubsection{Children from School Age to Adolescence Who Reassess Food Allergies in Life Models}

The process of coping with food allergies in young children may be greatly affected by the characteristics of the cognitive development of the child and the parents' cognitive assessment of food allergies.

When children enter school age, at around 7 - 11 years, the abilities needed to understand and reassess their own allergies, such as the ability to think about food allergies from a logical point of view with the development of recognition and the vocabulary to express allergic symptoms, are developed. Children who obtain security and safety by receiving reliable support for food allergies from adults show heightened interest in the mechanisms in their bodies and food allergies, judge how to take in food containing allergens as an active activity based on their own exploration, and proceed with the challenge. 
In other words, there is a reassessment (cognitive efforts) of the object of fear-the allergen - that the child had previously recognized as a threat that he/she could not handle, and he/she had transitioned to the stage of "challenging their allergens through trial and error".

The aim of challenging children at school age and onward was not primarily to achieve remission or to increase the amounts of tolerable allergen intake. Rather, they were encouraged to expand their abilities to live "well" with others who did not have food allergies.

Young children responded to the threat of allergens based on the medical model that was used as a standard by adults to make decisions, whereas school-age children challenged their food allergies through a Life model in which children are the main party involved. Thus, if the outcome of the challenge was unsatisfactory, the children considered it to be their failure.

Through the challenge of trial and error, children recognized allergies as a threat and took actions to cope by avoiding allergies from that point while living in a group with others, thus gaining "awareness that the threat of allergens could be minimized". Subsequently, the problems that arose when living with others while having allergies were structured by the idea of one's self, and it transitioned to the stage of "learning skills to live well without being constrained by allergies". The stage of challenging allergies was the transition from the stage in which allergies that were invisible enemies were avoided using emotional coping to the stage in which a reassessment was performed.

Children felt inconvenience with the constraints from food allergies in the Life model until the stage of pre-puberty and, even though they felt there were limitations in obtaining a cure for food allergies in the medical model, they understood that food allergies including constraint and limitations were part of their own uniqueness and were controllable objects and obtained a "sense of controlling constraints due to allergies".

These processes of cognition and coping with food allergies are considered to be progressing, including the development of sociality from school age onward, qualitative changes in the concept of self, and the value placed on the self with food allergies.

\subsection{Implications for Nursing Practice}

The coping behaviors of children with food allergies advanced in the judgment of the medical model as well as in the Life model in which children were the main party concerned. From this study, the following were considered important aspects of nursing care support for the child and caregivers of children with food allergies.

\subsubsection{Nurses Help Caregivers of Children with Food Allergies by Providing Appropriate Psychoeducational Support to their Children}

Many caregivers are an object of attachment to children and are an absolute 
safety base that can provide reassurance. Bowl by [12] notes that attachment behavior comprises various acts that attempt to keep a particular individual close and to maintain that closeness. These are most prominent when experiencing something scary or when ill. For children with bronchial asthma, Fukaya [13] reported that asthma attack-related breathlessness was a life-threatening experience; however, if adults who are objects of attachment are in the immediate vicinity, children feel a strong sense of security.

In children with food allergies, it is essential to gain a sense of security and safety by obtaining physical and psychological support for managing food allergies from caregivers around whom they feel secure. Furthermore, even school-aged children may have an increased need for reliable adult psychological support from the objects of their attachment when experiencing strong threats and new challenges from food allergies.

However, if the caregiver's fear of food allergies is high or if psychological support is not properly provided according to the child's needs, the child will not be able to acquire a sense of security from the caregiver. Not only will the child feel threatened because of the allergen due to food allergies but they will also feel a strong fluctuation in their perception of self and their bodies [14], and this may cause a decrease in their feelings of self-efficacy.

In order for a child with food allergies to understand their own food allergy as they grow and develop and learn to recognize it positively, there is a need to obtain affirmative reactions and associate optimistic meanings with food allergies. Also, a feeling of security and safety can be obtained from a familiar and trustworthy caregiver from early childhood with education about avoiding threats causing food allergies. Caregivers continuously providing this type of psychoeducational support for children with food allergies in their daily lives from the early childhood of such children can have long-term positive effects on children with food allergies.

The state of chronic illnesses in children is said to cause uncertainty in the psychology of caregivers [15]. Nurses should provide support to children with food allergies in terms of ensuring safe and appropriate medical care, both in terms of healthcare models and lifestyle models, and empower caregivers to make appropriate decisions and administer care to protect their children. It is also essential to assess the caregiver's fear and anxiety of food allergies in stressful conditions and to carry out interventions for reducing anxiety at an early stage.

\subsubsection{Nurses Should Present Risk-Avoiding Behaviors Related to Food Allergies to Young Children as Well as Reassessment and Actable Behaviors as Concrete Alternatives to Prohibited Behaviors}

The messages from parents along with episodes of early childhood allergies were more severe at that time, and the greater the caregiver's anxiety, the more intense the warnings that the allergy was life-threatening, which affected the child's coping behaviors. It is important not to instill fear of allergies and causal foods more than necessary as well as to only communicate prohibited behaviors 
and concretely present alternative behaviors (providing food that can be eaten and presenting recommended behaviors) that children can implement in their daily lives based on the child's cognitive development and experience. Additionally, it is necessary for the support of young children to provide a sense of security and improve their self-efficacy by performing actions together and becoming a model of the action.

Giving advice on how to provide concrete explanations to the child and how to deal with issues, from the viewpoint of child care support, after the prospect on growth and development and treatment of the child is communicated to the parents of children with food allergies, is also considered important.

\subsubsection{Nurses Should Assist with Identifying Problems with Allergies for School-Age and Older Children to Enable Problem-Centered Coping from the Viewpoint of the Medical and Life Model}

In early childhood, there were children who recognized allergens as threats that they could not deal with, who later regarded these as challenges through cognitive efforts from school age onward and in whom advances in problem-centered coping were observed. Children from school age to pre-puberty seek ways to manage food allergies and "how to do well" in their Life models, with an emphasis on maintaining relationships with friends and other people. At that stage, they tend to give priority to doing better in their Life models than to being safer at the medical level. As a nurse, it is important to provide educational support tailored to the child's cognitive development regarding the understanding of diseases required to protect health and life and how to deal with changes in physical conditions.

Additionally, for the independence of children's care behavior in the long-term, setting goals in small steps for problems that children themselves aim at in Life models as well as promotion in order to encourage problem-solving coping actions is required.

\section{Future Challenges}

From the results of this study, the coping process and necessity of support in children with food allergies were clarified. In nursing support provision, it is necessary to evaluate the stage of recognition and coping with food allergies as well as to devise and evaluate the possibility of utilization of long-term psychoeducational support guides for both the Medical and Life models. The target population of this study was mostly children actively tackling food allergies. Additionally, a guide plan should be developed that can be widely adapted to target individuals with problems such as children who have difficulty in independent care behavior from school age onward.

\section{Conclusions}

The process of coping in children developing food allergies in early childhood was stratified into the following 11 categories: "referring to food allergies as 
somebody else's business", "noticing 'their allergies' because they were different from others", "understanding their 'own allergy' from the knowledge they were taught and somatic sensations", "a vague fear of allergens", "eliminating the allergen that was the object of their fear", "fear of allergens that they could not handle by themselves", "seeking safety and security for one' s self and getting support", "challenging allergens through trial and error", "learning skills to live well without being constrained by allergies", "awareness that the threat of allergens could be minimized", and "sense of controlling allergy".

As support for children with food allergies, the need for nurses to evaluate the process of recognition and coping with food allergies based on the child's cognitive development and experiences as well as to evaluate psychoeducational support for promoting the child's coping behavior in both the medical and Life models while protecting the child's safety was indicated.

\section{Acknowledgements}

We are deeply grateful to all of the participants who provided valuable data during the performance of this study, and to all of the collaborated staff. And we would like to express my deep gratitude to Professor Kumi Suzuki, Associate Professor Xiaodong Cardenas of Osaka Medical University, Professor Junko Takemura of Kansai University of social Welfare who provided considered feedback and valuable comments.

\section{Funding}

We received the following financial support for the research, authorship, and/or publication of this article: This work was supported by JSPS KAKENHI(C)Grant Number JP15K11734.

\section{Conflicts of Interest}

We have no potential conflicts of interest with respect to the research, authorship, and publication of this article.

\section{References}

[1] Japan Society for Well-Being of Nursery-Scholars Allergy Countermeasure Committee (2011) Guidance for Allergies in a Nursery School. Japan Society for Well-Being of Nursery-Scholars Press, Tokyo. (In Japanese)

[2] Japan Society of School Health (2013) Survey on Health Management in School Life Report. Japan Society for Well-Being of Nursery-Scholars Press, Tokyo. (In Japanese)

[3] Imai, T. (2016) Epidemiology and Disease Type of Food Allergy. In: Itou, K., Ed., All about Food Allergies Basic, Clinical \& Social Landscapes, Shindan to Chiryosha, Tokyo, 21-28. (In Japanese)

[4] Japanese Society of Pediatric Allergy and Clinical Immunology (2018) Japanese Pediatric Guideline for Food Allergy 2016 (2018 Revision). Kyowa Kikaku, Tokyo. (In Japanese) 
[5] Japanese Society of Pediatric Allergy and Clinical Immunology (2005) Japanese Pediatric Guideline for Food Allergy 2005. Kyowa Kikaku, Tokyo. (In Japanese)

[6] Lazarus, R.S. and Folkman, S. (1984) Stress, Appraisal, and Coping. Springer Publishing Company, Inc., New York.

[7] Leventhal, H., Meyer, D. and Nerenz, D. (1980) The Common Sense Representation of Illness Danger. Medical Psychology, 2, 7-30.

[8] Kinoshita, Y. (2003) Modified Grounded Theory Approach. The Practice of the Grounded Theory Approach. Kobundo, Tokyo. (In Japanese)

[9] Shimokawa, N. and Ogishi, E. (2011) The Meaning of Food Allergy for Parents of Children with Food Induced Anaphylaxis. The Journal of Child Health, 70, 486-494. (In Japanese)

[10] Shimokawa, N. and Ryu, S. (2012) A Narrative Story of the Mothers Taking Care of Their Child for 9 Years with Food Induced Anaphylaxis. The Journal of Child Health, 71, 561-568. (In Japanese)

[11] Piajet, J. and Inhelder, B. (2019) The Psychology of the Child. Basic Book, New York.

[12] Bowlby, J. (1988) A Secure Base, Clinical Applications of Attachment Theory. Routledge, London.

[13] Fukaya, M. (2009) The Experience of Pulmonary Dyspnea by School-Aged Children with Bronchial Asthma. Journal of Japan Academy of Nursing Science, 29, 51-59. (In Japanese) https://doi.org/10.5630/jans.29.4_51

[14] Aoki, M. (2009) The Creation of a Natural Sense: The Self-Construction of Children with Congenital Heart Disease by Body-Image. Journal of Japan Academy of Nursing Science, 29, 43-51. (In Japanese) https://doi.org/10.5630/jans.29.3_43

[15] Knafl, K.A. and Santacroce, S.J. (2004) Chronic Conditions and the Family. In: Allen, P.J., Vessey, J.A. and Shapiro, N., Eds., Primary Care of the Child with a Chronic Condition, 4th Edition, Mosby, Maryland Heights, 74-89. 